\title{
Congenital Malformations Associated With a Single Umbilical Artery in Twin Pregnancies
}

\author{
Sarah E. Mitchell, ${ }^{1}$ Karen Reidy, ${ }^{2,3,4}$ Fabricio Da Silva Costa, ${ }^{1,2,3,4}$ Ricardo Palma-Dias, ${ }^{1,2,3,4}$ \\ Thomas J. Cade, ${ }^{1}$ and Mark P. Umstad ${ }^{1,4}$ \\ ${ }^{1}$ Division of Maternity Services, The Royal Women's Hospital, Melbourne, Victoria, Australia \\ ${ }^{2}$ Pregnancy Research Centre, The Royal Women's Hospital, Melbourne, Victoria, Australia \\ ${ }^{3}$ Pauline Gandel Imaging Centre, The Royal Women's Hospital, Melbourne, Victoria, Australia \\ ${ }^{4}$ Department of Obstetrics and Gynaecology, University of Melbourne, Victoria, Australia
}

A single umbilical artery (SUA) was identified in $1.5 \%$ of twin pregnancies. The presence of a SUA in a twin pregnancy was associated with a $50 \%$ incidence of fetal anomalies, many of them complex and severe. The embryology and pathophysiological mechanisms associated with a SUA are reviewed. Aneuploidy is relatively common and should be considered, particularly in the presence of associated anomalies. Fetal growth restriction is frequent and preterm delivery is common.

Keywords: twins, single umbilical artery, growth restriction, fetal anomalies

The incidence of a SUA in singleton pregnancies approximates 0.5\% (Granese et al., 2007; Hua et al., 2010), with a higher prevalence in twin pregnancies (Heifetz, 1984; Klatt et al., 2012). There is an association between a SUA and other concomitant congenital anomalies in both twin and singleton pregnancies, particularly those of the cardiac, renal, gastrointestinal, and central nervous systems (ArcosMachancoses et al., 2015; Chow et al., 1998). The possibility of aneuploidy in a fetus with a SUA also must be considered, with trisomies 13 and 18 the two most commonly reported associations (Chow et al., 1998; Dagklis et al., 2010).

Associated anomalies may be found with a SUA in up to $30 \%$ of cases in both twin and singleton pregnancies (Arcos-Machancoses et al., 2015; Chow et al., 1998; Klatt et al., 2012). This will inevitably lead a clinician to ruminate on whether a SUA is, in itself, a poor prognostic finding or whether it has an incidental association with these other more serious problems. In a previous study from our institution, we suggested that an isolated SUA in twin pregnancies increases the risk of preterm birth but no other poor pregnancy outcomes (Cade et al., 2014). The mechanism of spontaneous preterm birth is still poorly understood and it is difficult to make a case for causality of a SUA, thus it is somewhat debatable whether an isolated SUA truly confers a poorer prognosis in twins. When it is not isolated, it is worth considering if this finding is truly associated with a poor prognosis or if it is simply a marker that mandates a thorough sonographic search for coexistent anomalies.

We report on a 7.5-year experience of SUA in twin pregnancies complicated by coexistent anomalies, and aim to review the available literature about the formation of a SUA. We aim to define the common problems encountered in these pregnancies and the clinical implications of such findings.

\section{Patients and Methods}

We initially included all patients who had a twin pregnancy and a second trimester morphology ultrasound at the Royal Women's Hospital, Melbourne, over a 7.5-year period. Cases were identified using the hospital's Picture Archiving System (PACS; Viewpoint, GE Healthcare, Buckinghamshire, United Kingdom). For the purposes of this study, all patients with a documented finding of a SUA were initially reviewed, and those with any coexistent anomaly further examined. A review of placental histology or expert review of the ultrasound images by one of the authors (FDSC) was mandated for final inclusion.

All ultrasounds were performed at a tertiary obstetric unit by specialist obstetricians with expertise in obstetric ultrasound. Color Doppler was used to visualize the umbilical arteries, both adjacent to the fetal bladder and in a section of a free loop of cord. Fetal anomalies are described

RECEIVED 13 April 2015; ACCEPTED 14 July 2015. First published online 20 August 2015.

ADDRESS FOR CORRESPONDENCE: A/Prof Mark P. Umstad, Director of Maternity Services, The Royal Women's Hospital, 20 Flemington Road, Parkville, Victoria, Australia 3053. E-mail: mark.umstad@thewomens.org.au 
according to the post-mortem report, if available; otherwise the ultrasound findings are described.

This study was approved as an audit by the hospital's Human Research Ethics Committee.

\section{Results}

In the 7.5-year period of the study we provided care for 1,276 women with multiple pregnancies, 1,243 of which were twin pregnancies. There were initially 34 multiple pregnancies identified as having a SUA on ultrasound. Eleven were excluded due to placental histopathology findings of a three-vessel cord or because images were not available for expert review. One was excluded as there was fetal demise of one twin at 12 weeks. We excluded three triplet and one conjoined twin pregnancies. Of the remaining 18 pregnancies that were identified as having a SUA, nine were not associated with fetal anomalies and have been previously described (Cade et al., 2014). The remaining nine pregnancies, in which both an SUA and co-existent anomalies were found, are the subject of this analysis.

The mean maternal age at delivery was 31.1 (SD 2.6) years. Data on spontaneous versus assisted conception was either incomplete or unreliable so is not reported.

Five of the nine pregnancies were dichorionic diamniotic (DCDA), three were monochorionic diamniotic (MCDA), and one was monochorionic monoamniotic (MCMA). All twins, including monochorionic twins, were discordant both for SUAs and anomalies.

Table 1 details the findings and outcomes for dichorionic twins. Table 2 details the findings and outcomes for monochorionic twins. In each table the outcome is listed as normal if there were no residual concerns at the time of discharge.

In summary, the majority of fetal anomalies were cardiac or neurological in nature, with no specific pattern evident. Other anomalies included gastroenterological and renal. In all but two of the sets of twins, the non-SUA twin was normal. In the two with anomalies, both were renal in nature: a multicystic dysplastic kidney (case 3) and bilateral hydronephrosis (case 6).

The obstetric outcomes are detailed in Tables 1 and 2 and were frequently poor. As anticipated, both fetuses with trisomy 18 were perinatal deaths, as was the anencephalic fetus. The euploid fetuses with complex cardiac or neurological anomalies also succumbed. Preterm delivery was a common feature. The preterm deliveries were for suspected fetal compromise in growth-restricted fetuses in which the multiple fetal anomalies had not been identified (cases 2 and 8 ), for preterm premature rupture of membranes (cases 3 and 7), for twin-twin transfusion syndrome (case 6), electively at 32 weeks for MCMA twins (case 9) and spontaneous preterm labor secondary to polyhydramnios (case 4).

Karyotypes were available in 12 of the 18 fetuses (six of the nine with SUA). The only karyotype abnormality was trisomy 18, which was identified in two of the dichorionic fetuses (cases 1 and 5).

\section{Discussion}

In our series, the detection of a SUA on antenatal ultrasound in a twin pregnancy was associated with a $50 \%$ risk of fetal anomaly. Cardiac, neurological, and gastroenterological anomalies were the most frequent and were often severe. Aneuploidy was a significant association, with trisomy 18 observed in two of our nine cases of twins with a SUA and a fetal anomaly. The anomalies were frequently complex and often associated with poor perinatal outcome. Identification of a SUA on prenatal ultrasound in twins should prompt very careful surveillance for fetal anomalies. Even at our institution, with high level ultrasound expertise, many anomalies were not detected prior to delivery.

In the absence of an associated anomaly, there is a significant risk of preterm delivery (Cade et al., 2014). The presence of anomalies is even more significantly associated with preterm delivery with many of the deliveries resulting from iatrogenic prematurity. Only one of the nine twin pregnancies reached term.

Previous studies have shown an increased risk of growth restriction in twin pregnancies complicated by the presence of a SUA (Byers et al., 2013; Stout et al., 2013). Our previous research has shown that, in the absence of a fetal anomaly, growth restriction is not a feature (Cade et al., 2014). In contrast, this current review has demonstrated that the presence of a SUA associated with a fetal anomaly is frequently associated with fetal growth restriction. Given that this is a descriptive study and has not been controlled for confounders, this is an observation of interest and should be considered in the management of these patients.

The umbilical cord derives from the primitive yolk sac, the connecting stalk, and the amnion. By day 38, an angiogenic plexus forms around the allantoic duct and forms the umbilical vessels. A SUA initially develops, then with further development, bifurcates in the pelvis to form two umbilical arteries that originate from the right and left common iliac arteries (Monie, 1970; Persutte \& Hobbins, 1995).

An excellent comprehensive review of the proposed pathological mechanisms leading to a SUA has been provided by Persutte and Hobbins (1995). The first theory reviewed is that of primary agenesis of one umbilical artery. This would involve atresia of the vascular system from the umbilical bifurcation to the common iliac arteries and would invariably result in distal lower extremity abnormalities from ischemia. As these consequences are not seen, this theory can be dismissed.

The second theory reviewed is of persistence of the original allantoic artery. The authors argue that this is explained by failure of distal bifurcational migration. Support for this theory comes from the findings of a single cord artery that bifurcates in the fetal abdomen and communicates with 


\section{TABLE 1}

Perinatal Outcome for Dichorionic Twins

\begin{tabular}{|c|c|c|c|c|c|c|c|c|c|c|c|c|c|c|c|}
\hline \multirow[b]{3}{*}{ Case } & \multirow[b]{3}{*}{$\begin{array}{l}\text { Maternal } \\
\text { age } \\
\text { (years) }\end{array}$} & \multirow[b]{3}{*}{$\begin{array}{l}\text { Mode of } \\
\text { delivery }\end{array}$} & \multirow{3}{*}{$\begin{array}{l}\text { Gestation } \\
\text { at } \\
\text { delivery } \\
\text { (weeks) }\end{array}$} & \multicolumn{12}{|c|}{ Perinatal outcomes } \\
\hline & & & & \multicolumn{6}{|c|}{ SUA twin } & \multicolumn{6}{|c|}{ Co-twin } \\
\hline & & & & Sex & Karyotype & $\begin{array}{l}\text { Birthweight } \\
\text { (g) }\end{array}$ & $\begin{array}{l}\text { Birthweight } \\
\text { percentile }\end{array}$ & Anomalies & Outcome & Sex & Karyotype & $\begin{array}{l}\text { Birthweight } \\
\text { (g) }\end{array}$ & $\begin{array}{l}\text { Birthweight } \\
\text { percentile }\end{array}$ & Anomalies & Outcome \\
\hline 1 & 38 & Vaginal & 35 & $\mathrm{~F}$ & $\begin{array}{c}\text { Trisomy } \\
18\end{array}$ & 898 & $<1 \%$ & $\begin{array}{l}\text { Holoprosencephaly; } \\
\text { hypotelorism; } \\
\text { diaphragmatic } \\
\text { hernia; AVSD; left } \\
\text { ventricle smaller than } \\
\text { right ventricle; single } \\
\text { nostril }\end{array}$ & $\begin{array}{r}\text { NND at } 20 \\
\text { minutes }\end{array}$ & $\mathrm{F}$ & Normal & 2,676 & $75 \%$ & Nil & Normal \\
\hline 2 & 19 & $\begin{array}{c}\text { Emergency } \\
\text { LUSCS }\end{array}$ & 28 & $M$ & No & 730 & $3 \%$ & $\begin{array}{l}\text { Enlarged pulmonary } \\
\text { trunk; right sided } \\
\text { aortic arch; vascular } \\
\text { ring; tracheomalacia; } \\
\text { patent ductus } \\
\text { arteriosus; patent } \\
\text { foramen ovale; } \\
\text { inguinal hernia }\end{array}$ & $\begin{array}{l}\text { Alive but } \\
\text { continuing } \\
\text { cardiac and } \\
\text { respiratory } \\
\text { care }\end{array}$ & $M$ & No & 890 & $10 \%$ & Nil & Normal \\
\hline 3 & 28 & $\begin{array}{c}\text { Emergency } \\
\text { LUSCS }\end{array}$ & 30 & $\mathrm{~F}$ & Normal & 662 & $<1 \%$ & $\begin{array}{l}\text { Pentalogy of Cantrell; } \\
\text { tetralogy of Fallot; } \\
\text { exomphalos; } \\
\text { kyphosis; partial } \\
\text { agenesis of vermis; }\end{array}$ & $\begin{array}{l}\text { Selective } \\
\text { termination } \\
\text { at } 29 \text { weeks }\end{array}$ & $\mathrm{F}$ & Normal & 1,372 & 85th & $\begin{array}{c}\text { Multicystic } \\
\text { dysplastic } \\
\text { kidney }\end{array}$ & $\begin{array}{l}\text { Discharged } \\
\text { home but } \\
\text { continuing } \\
\text { renal } \\
\text { follow-up }\end{array}$ \\
\hline 4 & 30 & Vaginal & 32 & $\mathrm{~F}$ & Normal & $3,345^{b}$ & $>99 \%$ & $\begin{array}{l}\text { Hydrothorax; severe } \\
\text { right cerebral } \\
\text { ventriculomegaly; } \\
\text { macrocrania; } \\
\text { hydrops fetalis; } \\
\text { polyhydramnios }\end{array}$ & $\begin{array}{c}\text { FDIU at } 31 \\
\text { weeks }\end{array}$ & $\mathrm{F}$ & Normal & 1,700 & $60 \%$ & Normal & Normal \\
\hline 5 & 41 & $\begin{array}{l}\text { Elective } \\
\quad \text { LUSCS }\end{array}$ & 39 & $\mathrm{~F}$ & $\begin{array}{c}\text { Trisomy } \\
18\end{array}$ & 2,040 & $3 \%$ & $\begin{array}{l}\text { Choroid plexus cysts; } \\
\text { brachycephaly; } \\
\text { hypoplastic } \\
\text { cerebellum; bilateral } \\
\text { overlapping fingers; } \\
\text { polyhydramnios }\end{array}$ & NND day 8 & M & No & 3,065 & $65 \%$ & Normal & Normal \\
\hline
\end{tabular}

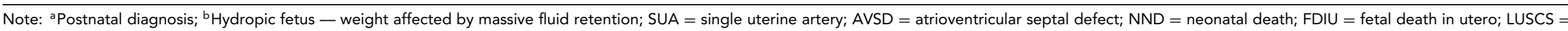
lower uterine segment cesarean section. 
TABLE 2

Perinatal Outcome of Monochorionic Twins

\begin{tabular}{|c|c|c|c|c|c|c|c|c|c|c|c|c|c|c|c|}
\hline \multirow[b]{3}{*}{ Case } & \multirow[b]{3}{*}{$\begin{array}{l}\text { Maternal } \\
\text { age } \\
\text { (years) }\end{array}$} & \multirow[b]{3}{*}{$\begin{array}{l}\text { Mode of } \\
\text { delivery }\end{array}$} & \multirow{3}{*}{$\begin{array}{l}\text { Gestation } \\
\text { at } \\
\text { delivery } \\
\text { (weeks) }\end{array}$} & \multicolumn{12}{|c|}{ Perinatal outcomes } \\
\hline & & & & \multicolumn{6}{|c|}{ SUA twin } & \multicolumn{6}{|c|}{ Co-twin } \\
\hline & & & & Sex & Karyotype & $\begin{array}{l}\text { Birthweight } \\
\text { (g) }\end{array}$ & $\begin{array}{l}\text { Birthweight } \\
\text { percentile }\end{array}$ & Anomalies & Outcome & Sex & Karyotype & Birthweight & $\begin{array}{l}\text { Birthweight } \\
\text { percentile }\end{array}$ & Anomalies & Outcome \\
\hline 6 & 35 & $\begin{array}{l}\text { Emergency } \\
\text { LUSCS }\end{array}$ & 30 & M & Normal & 1,095 & $5 \%$ & $\begin{array}{l}\text { Coarctation of the } \\
\text { aorta; patent ductus } \\
\text { arteriosus; patent } \\
\text { foramen ovale; } \\
\text { bilateral } \\
\text { hydronephrosis } \\
\text { a }\end{array}$ & $\begin{array}{l}\text { Excellent } \\
\text { result from } \\
\text { cardiac } \\
\text { surgery }\end{array}$ & M & No & 1,545 & $60 \%$ & $\begin{array}{l}\text { Bilateral hy- } \\
\text { dronephro- } \\
\text { sis; patent } \\
\text { ductus } \\
\text { arteriosus }\end{array}$ & Normal \\
\hline 7 & 34 & $\begin{array}{l}\text { Emergency } \\
\text { LUSCS }\end{array}$ & 32 & M & Normal & 1,560 & $20 \%$ & $\begin{array}{l}\text { Anencephaly; } \\
\text { rachischisis involving } \\
\text { cervical and thoracic } \\
\text { vertebrae; } \\
\text { exomphalos; absent } \\
\text { right ulna and radius; } \\
\text { abnormal right hand; } \\
\text { scoliosis }\end{array}$ & $\begin{array}{c}\text { NND at } 12 \\
\text { minutes }\end{array}$ & M & Normal & 2,090 & $80 \%$ & Nil & Normal \\
\hline 8 & 36 & $\begin{array}{l}\text { Emergency } \\
\text { LUSCS }\end{array}$ & 27 & $\mathrm{~F}$ & Normal & 529 & $<1 \%$ & $\begin{array}{l}\text { Coarctation of the } \\
\text { aorta; left ventricular } \\
\text { dilatation; patent } \\
\text { ductus arteriosus }\end{array}$ & $\begin{array}{l}\text { Repair of } \\
\text { coarcta- } \\
\text { tion. } \\
\text { Bron- } \\
\text { chopul- } \\
\text { monary } \\
\text { dysplasia } \\
\text { with } \\
\text { continuing } \\
\text { respiratory } \\
\text { care } 250 \\
\text { days after } \\
\text { delivery }\end{array}$ & $\mathrm{F}$ & Normal & 909 & $35 \%$ & Nil & Normal \\
\hline $9^{b}$ & 19 & $\begin{array}{l}\text { Elective } \\
\text { LUSCS }\end{array}$ & 32 & M & No & 1,500 & $15 \%$ & Absent left lung & $\begin{array}{l}\text { Continuing } \\
\text { cardiotho- } \\
\text { racic } \\
\text { follow-up }\end{array}$ & M & No & 1,740 & $40 \%$ & Nil & Normal \\
\hline
\end{tabular}

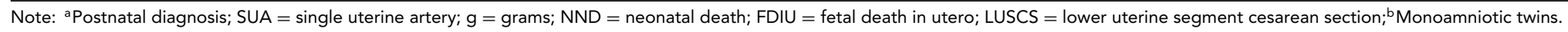


both common iliac arteries. Further support is from the observation that the incidence of a SUA increases the closer to the placenta that the cord is inspected.

The third theory, and the most likely explanation for the pathology of a SUA, is secondary atresia or atrophy of a previously normal umbilical artery. In support of this theory is the fact that pathologists can identify, on close inspection, allantoic derivatives or arterial remnants in the cord. Luminal bridging to the other umbilical artery has also been described, with portions of the same umbilical cord containing both one and two umbilical arteries, suggesting a mechanical disruption leading to secondary atrophy.

A final, and very rare causation, seen in sirenomelia is failure of regression of vitelline-derived vasculature.

Martinez-Frias et al. (2008) offer alternative explanations with four groups identified according to the associated fetal abnormalities. The first group corresponds to patterns of defects that occur early during embryogenesis and are associated with body stalk defects and sirenomelia.

The second group includes those that have strong associations between the presence of a SUA and specific fetal defects, with the suggestion that errors occur during blastogenesis, resulting in the well-known associations of esophageal atresia, imperforate anus, renal defects and vertebral defects. It has been proposed that these are caudal defect variations of the sirenomelia continuum.

The third group includes central nervous system defects, cardiac defects, and unilateral renal agenesis that also arise during blastogenesis. It is not clear to us how this group differs from the second group described by Martinez-Frias et al. (2008).

Their fourth group described includes those fetuses with a SUA and patterns of multiple congenital anomalies, including intestinal atresia, limb deficiencies, and vascular defects.

We find the Persutte and Hobbins (1995) hypotheses a more intuitive, clinically sound and considered explanation, but acknowledge the complexity and lack of universal agreement in this area. However, the conclusions of Martinez-Frias et al. (2008) are to be commended. They conclude that SUAs have different origins, different pathogenetic mechanisms, and are mediated by different genetic and environmental factors, which in turn result in different clinical outcomes.

In practice, the diagnosis of a SUA in a twin pregnancy is uncommon, with an incidence in our cohort of $0.72 \%$, lower than previous studies (Heifetz, 1984; Klatt et al., 2012; Stout et al., 2013). The lower incidence in our cohort is possibly because we mandated a histopathological diagnosis of SUA in the placenta postnatally or review of ultrasound images by a single experienced operator. We cannot calculate an accurate incidence because not all twin pregnancies have had the same scrutiny of ultrasound and histopathology as the cases with SUA (Cade et al., 2014).
Half of the pregnancies identified had no fetal anomalies; of the remaining half, even in a center with high level ultrasound surveillance of multiple pregnancies, not all of the anomalies were detected. In our series of 18 patients, the only two with aneuploidy had multiple significant anomalies that could be easily identified. We suggest that amniocentesis should only be considered in the presence of fetal anomalies. This finding, and advice, is consistent with previous studies (Gornall et al., 2003; Voskamp et al., 2013).

Careful postnatal follow-up is required even in the absence of antenatal ultrasound detection of anomalies.

\section{Conclusion}

The identification of a SUA in a twin pregnancy should prompt a very careful search for a fetal anomaly on ultrasound. Aneuploidy should be considered, particularly in the presence of a fetal anomaly. Preterm delivery is frequent and is often iatrogenic.

\section{References}

Arcos-Machancoses, J. V., Marín-Reina, P., Romaguera-Salort, E., García-Camuñas, Y., Pérez-Aytés, A., \& Vento, M. (2015). Postnatal development of fetuses with a single umbilical artery: Differences between malformed and nonmalformed infants. World Journal of Paediatrics, 11, 61-66.

Byers, B. D., Saade, G. R., \& Harirah, H. M. (2013). Twin pregnancies discordant for single umbilical artery. Journal of Reproductive Medicine, 58, 241-245.

Cade, T. J., Da Silva Costa, F., Reidy, K., Doyle, L., Mitchell, S. E., Palma-Dias, R., \& Umstad, M. P. (2014). Pregnancy prognosis associated with an isolated single umbilical artery in twin pregnancy. Twin Research and Human Genetics, 17, 584-588.

Chow, J. S., Benson, C. B., \& Doubilet, P. M. (1998). Frequency and nature of structural anomalies in fetuses with single umbilical arteries. Journal of Ultrasound in Medicine, 17, 765-768.

Dagklis, T., Defigueiredo, D., Staboulidou, I., Casagrandi, D., \& Nicolaides, K. H., (2010). Isolated single umbilical artery and fetal karyotype. Ultrasound in Obstetrics and Gynecology, 36, 291-295.

Gornall, A. S., Kurinczuk, J. J., \& Konje, J. C. (2003). Antenatal detection of a single umbilical artery: Does it matter? Prenatal Diagnosis, 23, 117-123.

Granese, R., Coco, C., \& Jeanty, P. (2007). The value of single umbilical artery in the prediction of fetal aneuploidy: Findings in 12,672 pregnant women. Ultrasound Quarterly, 23, 117-121.

Heifetz, S. A. (1984). Single umbilical artery. A statistical analysis of 237 autopsy cases and review of the literature. Perspectives in Pediatric Pathology, 8, 345-378.

Hua, M., Odibo, A. O., Macones, G. A., Roehl, K. A., Crane, J. P., \& Cahill, A. G. (2010). Single umbilical artery and its associated findings. Obstetrics and Gynecology, 115, 930934. 
Klatt, J., Kuhn, A., Baumann, M., \& Raio, L. (2012). Single umbilical artery in twin pregnancies. Ultrasound in Obstetrics and Gynecology, 39, 505-509.

Martinez-Frias, M. L., Bermejo, E., Rodriguez-Pinilla, E., Prieto, D., \& ECEMC Working Group. (2008). Does single umbilical artery (SUA) predict any type of congenital defect? Clinical-epidemiological analysis of a large consecutive series of malformed infants. American Journal of Medical Genetics Part A, 146A, 15-25.

Monie, I. W. (1970). Genesis of single umbilical artery. American Journal of Obstetrics and Gynecology, 108, 400-405.

Persutte, W. H., \& Hobbins, J. (1995). Single umbilical artery: A clinical enigma in modern prenatal diagno- sis. Ultrasound in Obstetrics and Gynecology, 6, 216229.

Stout, M. J., Obido, A. O., Longman, R., Shanks, A. L., \& Cahill, A. G. (2013). The incidence of isolated single umbilical artery in twins and adverse pregnancy outcomes. Prenatal Diagnosis, 33, 269-272.

Voskamp, B. J., Fleurke-Rozema, H., Oude-Rengerink, K., Snijders, R. J. M., Bilardo, C. M., Mol, B. W. J., \& Pajkrt, E. (2013). Relationship of isolated single umbilical artery to fetal growth, aneuploidy and perinatal mortality: Systematic review and meta-analysis. Ultrasound in Obstetrics and Gynecology, 42, 622628. 